\title{
Enhanced Sucrose and Cocaine Self-Administration and Cue-Induced Drug Seeking after Loss of VGLUT2 in Midbrain Dopamine Neurons in Mice
}

\author{
Johan Alsiö, ${ }^{1}$ Karin Nordenankar, ${ }^{1}$ Emma Arvidsson, ${ }^{1}$ Carolina Birgner, ${ }^{1}$ Souha Mahmoudi, ${ }^{2}$ Briac Halbout, ${ }^{4}$ \\ Casey Smith, ${ }^{1}$ Guillaume M. Fortin, ${ }^{5}$ Lars Olson, ${ }^{6}$ Laurent Descarries, ${ }^{3}$ Louis-Éric Trudeau, ${ }^{5}$ Klas Kullander, ${ }^{1}$ \\ Daniel Lévesque, ${ }^{2}$ and Åsa Wallén-Mackenzie ${ }^{1}$ \\ ${ }^{1}$ Department of Neuroscience, Unit of Developmental Genetics, Uppsala University, S-751 24 Uppsala, Sweden, ${ }^{2}$ Faculty of Pharmacy and ${ }^{3}$ Departments of \\ Pathology and Cell Biology and of Physiology, CNS Research Group, Faculty of Medicine, Université de Montréal, Montréal, H3C 3J7 Quebec, Canada, \\ ${ }^{4}$ Department of Psychopharmacology, Central Institute of Mental Health, 68159 Mannheim, Germany, ${ }^{5}$ Department of Pharmacology, CNS Research Group, \\ Faculty of Medicine, Université de Montréal, Montréal, H3C 3J7 Quebec, Canada, and ${ }^{6}$ Department of Neuroscience, Karolinska Institutet, S-171 77 \\ Stockholm, Sweden
}

The mesostriatal dopamine(DA) system contributes to several aspects of responses to rewarding substances and is implicated in conditions such as drug addiction and eating disorders. A subset of DA neurons has been shown to express the type 2 Vesicularglutamate transporter (Vglut2) and may therefore corelease glutamate. In the present study, we analyzed mice with a conditional deletion of Vglut2 in DA neurons (Vglut $2^{f f ; D A T-C r e}$ ) to address the functional significance of the glutamate-DA cophenotype for responses to cocaine and food reinforcement. Biochemical parameters of striatal DA function were also examined by using DA receptor autoradiography, immediate-early gene quantitative in situ hybridization after cocaine challenge, and DA-selective in vivo chronoamperometry. Mice in which Vglut2 expression had been abrogated in DA neurons displayed enhanced operant self-administration of both high-sucrose food and intravenous cocaine. Furthermore, cocaine seeking maintained by drug-paired cues was increased by $76 \%$, showing that reward-dependent plasticity is perturbed in these mice. In addition, several lines of evidence suggest that adaptive changes occurred in both the ventral and dorsal striatum in the absence of VGLUT2: DA receptor binding was increased, and basal mRNA levels of the DA-induced early genes Nur77 and c-fos were elevated as after cocaine induction. Furthermore, in vivo challenge of the DA system by potassium-evoked depolarization revealed less DA release in both striatal areas. This study demonstrates that absence of VGLUT2 in DA neurons leads to perturbations of reward consumption as well as reward-associated memory, features of particular relevance for addictive-like behavior.

\section{Introduction}

The mesostriatal dopamine (DA) system constitutes a central component of the brain reward circuitry. Midbrain DA projections to the nucleus accumbens (NAc) in the ventral striatum as

Received May 12, 2011; revised July 16, 2011; accepted July 18, 2011.

Author contributions: J.A., C.B., B.H., D.L, and Å.W.-M. designed research; J.A., K.N., E.A., C.B., S.M., B.H., G.M.F., and A..W.-M. performed research; L.0., K.K., and D.L. contributed unpublished reagents/analytic tools; J.A., K.N., E.A., C.B., S.M., C.S., G.M.F., L.O., L.D., L.E.T., K.K., D.L., and Å.W.-M. analyzed data; J.A., B.H., C.S., L.O., L.D., L.E.T., K.K., D.L., and Å.W.-M. wrote the paper.

This work was supported by grants from the Swedish Research Council Medicine (2007-5742/3630/4479, 2010-4394, 03185-39), The National Board of Health and Welfare (Socialstyrelsen), The Swedish Foundation for International Cooperation in Research and Higher Education, Uppsala University, the Swedish Brain Foundation, Swedish Brain Power, and the foundations of Hållsten, Göran Gustafsson, Åke Wiberg, and Åhlén, Sweden. J.A. was partly supported by the Swedish Academy of Pharmaceutical Sciences. Fonds de la Recherche en Santé du Québec provided infrastructure funding (Groupe de Recherche surleSystème Nerveux (entral) to L.D. and L.-E.T.K.K. is a Royal Swedish Academy of Sciences Research Fellow supported by a grant from the Knut and Alice Wallenberg Foundation. We thank Prof. N.-G. Larsson for sharing the DAT-Cre mouse line, Dr. M. Lundblad and Prof. G. A. Gerhardt for sharing their expertise in in vivo amperometry, and Prof. S. El Mestikawy for critical reading of this manuscript.

L.O. is co-owner of a company owning the commercial rights to a genetic mouse model of Parkinson's disease, the generation of which requires use of the DAT-Cre mouse. No other potential conflicts of interest were reported.

Correspondence should be addressed to Assa Wallén-Mackenzie, Department of Neuroscience, Unit of Developmental Genetics, Biomedical Center,P.0. Box593,Uppsala University,S-75124Uppsala,Sweden.E-mail:asa.mackenzie@neuro.uu.se.

DOI:10.1523/JNEUROSCI.2397-11.2011

Copyright $\odot 2011$ the authors $\quad 0270-6474 / 11 / 3112593-11 \$ 15.00 / 0$ well as to the dorsal striatum (DStr) are important for functions such as reward associative learning, seeking, and consumption. DA release in the NAc is induced by both natural stimuli, such as food (Bassareo and Di Chiara, 1999), and by drugs of abuse (Di Chiara and Imperato, 1988). Consequently, dysfunction of the mesostriatal DA system is implicated in reward-related disorders such as cocaine addiction (Volkow et al., 2008) and overeating in the context of obesity (Wang et al., 2001; Stice et al., 2008). The highly addictive properties of cocaine are thought to be mediated, in part, by blockage of DA reuptake, leading to increased DA levels throughout the striatum (Giros et al., 1996). Repeated cocaine intake leads to the establishment of sustained neuroadaptations in both the NAc and DStr that contribute to the development of addiction (Pulipparacharuvil et al., 2008; Wolf, 2010; Luscher and Malenka, 2011).

Midbrain DA neurons have been shown to express the Vesicular glutamate transporter 2 (Vglut2) and are thus able to package and release glutamate (for review, see El Mestikawy et al., 2011). The behavioral relevance of this dual glutamate-DA cophenotype is mostly unexplored; however, several novel lines of evidence have suggested a role in reward-related functions. First, DA 
neurons in the adult mouse ventral tegmental area (VTA) possess the ability to release glutamate in the NAc under physiological conditions (Stuber et al., 2010; Tecuapetla et al., 2010) in a VGLUT2-dependent manner (Stuber et al., 2010), and in response to stimulation mimicking reward-related activation of these neurons (Tecuapetla et al., 2010). Second, conditional knockout (cKO) mice lacking VGLUT2 specifically in DA neurons display altered locomotor responsiveness to the psychostimulants amphetamine (Birgner et al., 2010) and cocaine (Hnasko et al., 2010). Third, slices obtained from such cKO mice show decreased DA release in the NAc (Hnasko et al., 2010).

In light of these recent advances, it becomes critical to address the putative role of the glutamate-DA cophenotype in reward processing and addictive-like behavior. To explore this issue, we analyzed the recently described cKO mice (Birgner et al., 2010) in procedures of operant self-administration of both natural reward (i.e., sweet food) and cocaine. We report that the cKO mice showed elevated self-administration of both high-sugar food and cocaine and also displayed enhanced cocaine seeking in response to cocaine-associated cues. Furthermore, biochemical analyses revealed significant alterations in both NAc and DStr, including increased DA receptor binding and expression of DA-regulated immediate-early genes (IEGs) and decreased DA levels in response to in vivo challenge of the DA axon terminals by potassium-evoked depolarization. These findings suggest that the loss of VGLUT2 in DA cells produces profound alterations in the mechanisms regulating consumption of both natural and drug reward, as well as drug seeking triggered by drug-associated cues. Thus, the glutamatergic cophenotype of DA neurons may be of relevance for addiction susceptibility.

\section{Materials and Methods}

Animals. All animal procedures followed Swedish (Animal Welfare Act SFS1998:56) and European Union (Convention ETS123 and Directive 2010/63/EU) legislation and were approved by the Uppsala Ethical Committee for Use of Animals. Mice were housed in constant temperature $\left(21 \pm 1^{\circ} \mathrm{C}\right)$ and humidity $(50-60 \%)$ with two to four mice per cage unless stated otherwise. All behavioral experiments took place during the light phase, between 6:30 A.M. and 6:30 P.M. Food (R3; Lactamin/Lantmännen) and water were provided ad libitum unless stated otherwise. All animals used in behavior studies were adult ( $\geq 8$ weeks of age) and habituated to handling for $7 \mathrm{~d}$ before experiments.

By crossing Vglut2 ${ }^{f / f}$ mice (Wallén-Mackenzie et al., 2006; WallénMackenzie et al., 2009) with DAT-Cre mice (Ekstrand et al., 2007), as described previously (Birgner et al., 2010), both Vglut2 $2^{f / D A T-C r e}$ cKO and Vglut $2^{f f f}$ control (Ctrl) mice (which do not express the DAT-Cre transgene and therefore have normal Vglut2 expression) were produced in the same litters. Thus, $\mathrm{cKO}$ and Ctrl mice were of the same genetic background, a hybrid of C57/BL6 and Sv129. Genotyping was performed as described previously (Wallén-Mackenzie et al., 2006).

Sucrose bottle preference test. Nineteen male mice (cKO, $n=10$; Ctrl, $n=9$ ) were singly housed throughout the experiment to allow individual fluid intake measurements. The mice had ad libitum access to rodent chow at all times. After $48 \mathrm{~h}$ of adaptation to the experimental set up (two bottles of water), the mice had access to sucrose solution in one bottle and tap water in a second one for the remainder of the experiment. Water and sucrose solutions were replaced every $24 \mathrm{~h}$ (bottle positions alternated from left to right to minimize side bias) and weighed to measure consumption. Each concentration was tested for $48 \mathrm{~h}$ and presented in an increasing order: $0.3,1.0,3.0,10$, and $30 \%$. All measurements were corrected for spillage by subtracting the average loss of fluid from bottles placed in two empty cages. Sucrose preference was defined as higher consumption of sucrose than water using paired $t$ tests.

Operant self-administration apparatus and food self-administration procedure. Instrumental training was performed in operant chambers (MED Associates) with nosepoke devices situated on each side of a food pellet receptacle. Behavior was recorded via the MED-PC computer interface and MED-PC version 4 software control system. Responding at the active nosepoke (right) aperture activated a food dispenser and resulted in the delivery of a single $20 \mathrm{mg}$ food pellet (5TUL; TestDiet), according to fixed ratio (FR) or progressive ratio (PR) schedules. Time out after a reinforcer was $10 \mathrm{~s}$, during which time the stimulus light above the active nosepoke aperture was turned on. In addition, a brief burst of clicks accompanied each delivery of a food pellet. FR sessions lasted 60 min, whereas PR sessions were $90 \mathrm{~min}$. No maximum number of pellets was set unless stated. Each measurement point was the mean value of 3 consecutive stable days of responding $( \pm 30 \%)$.

Operant self-administration of food/sucrose. Twelve male mice initially were used to investigate whether the acquisition of the nosepoke response task was impaired in the $\mathrm{cKO}$ mice ( $\mathrm{cKO}, n=6$; Ctrl, $n=6)$. These mice were restricted to receive $3 \mathrm{~g}$ of rodent chow (R3; Lactamin/ Lantmännen) each day at 6:00 P.M. One operant session per day was allowed, and no more than 30 precision pellets could be obtained in a session. Rate of acquisition was defined as the number of days before a given animal had had 3 consecutive days with 30 reinforcers on fixed ratio 1 (FR1). One cKO mouse did not reach this criterion and was excluded. After acquisition, the response requirement was gradually increased to FR5, and the number of pellets obtained on FR5 was also compared between groups.

Eighteen male mice (cKO, $n=9$; Ctrl, $n=9$ ), singly housed, were next used in a two-phase study. In the first phase, these mice were food restricted (as above) and acquired the nosepoke response task motivated by low-sucrose grain-based pellets (5TUM; TestDiet) in the operant chambers. The response requirement was gradually increased to FR5. After 3 stable days on FR5 (no limit to number of reinforcers), the animals were analyzed on a PR schedule; on this schedule, response requirement for each pellet during the session was calculated according to the formula $5 e^{\text {(reinforcement number } \times 0.2)}-5$, rounded to the nearest integer (Richardson and Roberts, 1996). After stable PR measurements for 5TUM, the mice received ad libitum access to standard chow in the home cage for the remainder of the experiment. After a $3 \mathrm{~d}$ acclimatization period without operant testing, animals entered the second phase of the experiments, during which responding on FR5 and PR was measured for the high-sucrose pellets (5TUL). Food intake in the home cage was measured each day to calculate the percentage of energy consumed from the high-sugar pellets.

The number of nosepokes on the active and inactive manipulanda, as well as the total number of reinforcers earned on each of the schedules (FR5 and PR) and pellet types (5TUM and 5TUL), were compared between genotypes. Food intake during ad libitum conditions (before operant training) and refeeding (immediately after food restriction period ended and mice were put back on ad libitum food supply) was also measured. Total daily food intake (home cage plus reinforcers) was calculated along with the percentage of total intake from highsucrose pellets.

Operant intravenous self-administration of cocaine. Twenty-two male mice were 8-9 weeks old at the start of food training. Animals acquired the nosepoke response task for sucrose pellets during mild food restriction (as above). Subsequently, food restriction was lifted, and the mice had ad libitum access to regular food chow (R3; Lactamin/Lantmännen) throughout the rest of the study. Four animals did not acquire the nosepoke response task ( $\mathrm{cKO}, n=3 ; \mathrm{Ctrl}, n=1)$ and were thus excluded from the experiment.

After at least $3 \mathrm{~d}$ on ad libitum access to food, the mice underwent surgery under isoflurane anesthesia for the implantation of an intravenous catheter into the right jugular vein. The catheter was filled with a heparin/Baytril solution to prevent clogging. After $3 \mathrm{~d}$ of postsurgery recovery, the mice were reintroduced into the operant chamber. Acquisition of cocaine responding was performed at $0.5 \mathrm{mg} / \mathrm{kg}$ per infusion. Nosepoke responding during this phase activated a syringe pump delivering cocaine infusions through the catheter and illuminated a flashing light stimulus. Time out after an infusion was $20 \mathrm{~s}$. An intermediate progressive ratio schedule was used (six infusions on FR1 followed by four infusions on FR2 and the remainder on FR4) during 
the first session on each cocaine concentration throughout the study (not analyzed).

Seventeen mice (cKO, $n=8$; Ctrl, $n=9$ ) had patent catheters and acquired the operant response for cocaine on an FR4 schedule. One statistical outlier was detected in the Ctrl group (active nosepoke response 2.6-34.0 SEs above the mean depending on the infusion dose) and removed from analysis. The mice were subsequently tested on different doses according to a Latin square design (per infusion: 0.125, 0.25, and $1.0 \mathrm{mg} / \mathrm{kg}$ ). As a last step, all animals responded for $0.0625 \mathrm{mg} / \mathrm{kg}$ per infusion.

All data presented for cocaine responding stand for the mean of three consecutive stable sessions on an FR4 schedule (i.e., $\pm 30 \%$ on infusions or active nosepoke response) except on the 0.0625 dose where responding was low and not always stable; on this dose, 3 consecutive days with four or less infusions or 3 stable days (as above) was used to collect a measurement point.

Catheter integrity and patency was evaluated if behavior was erratic; anesthesia within $3 \mathrm{~s}$ after an injection of $20 \mu$ l of a mixture of midazolam $(0.75$ $\mathrm{mg} / \mathrm{ml}$ ) and ketamine $(15 \mathrm{mg} / \mathrm{ml}$ ) was used to confirm patency (Thomsen and Caine, 2006). If a mouse failed the catheter patency test, data from erratic and subsequent sessions were excluded from the analysis.

Cocaine seeking after abstinence. Mice from the cocaine selfadministration experiment were used to measure cocaine seeking ( $\mathrm{cKO}$, $n=6$; Ctrl, $n=5$ ). First, all animals responded for 3 stable days on 0.75 $\mathrm{mg} / \mathrm{kg}$ per infusion. The mice were then returned to their home cages for $21 \mathrm{~d}$, after which cocaine seeking was tested in the operant chambers. During this session, nosepoke response (FR4) resulted in the presentation of cocaine-associated cues (stimulus light and syringe pump sound), but no cocaine infusions.

DA receptor autoradiography. After decapitation of male mice (cKO, $n=8$; Ctrl, $n=9$ ), brains were rapidly removed and immediately immersed into cold isopentane $\left(-40^{\circ} \mathrm{C}\right)$. For $\mathrm{D}_{1}$ receptor $\left(\mathrm{D}_{1} \mathrm{R}\right)$ binding, brain sections were preincubated in a buffer containing $15 \mathrm{~mm}$ Tris- $\mathrm{HCl}$, $120 \mathrm{~mm} \mathrm{NaCl}, 5 \mathrm{~mm} \mathrm{KCl}, 2 \mathrm{~mm} \mathrm{CaCl}, 1 \mathrm{~mm} \mathrm{MgCl}, 0.1 \%$ ascorbic acid, and $0.1 \mathrm{~mm}$ EDTA, $\mathrm{pH} 7.4$, for $15 \mathrm{~min}$ at room temperature and incubated in the same buffer containing $2 \mathrm{~nm}\left[N\right.$-methyl- $\left.{ }^{3} \mathrm{H}\right] \mathrm{SCH} 23390$ (specific activity, $85 \mathrm{Ci} / \mathrm{mmol}$; GE Healthcare) for $1 \mathrm{~h}$ at room temperature. A concentration of $1 \mu \mathrm{M} \mathrm{SCH} 23390$ (Sigma-Aldrich) was used to determine nonspecific binding. The sections were rinsed three times ( 1 min each) in ice-cold $50 \mathrm{~mm}$ Tris- $\mathrm{HCl}$ plus $120 \mathrm{~mm} \mathrm{NaCl}$ buffer and dipped for a few seconds in distilled water. For $\mathrm{D}_{2}$ receptor binding, a buffer containing $50 \mathrm{~mm}$ Tris- $\mathrm{HCl}, 120 \mathrm{~mm} \mathrm{NaCl}, 5 \mathrm{~mm} \mathrm{KCl}, 1.5 \mathrm{~mm}$ $\mathrm{CaCl}_{2}, 4 \mathrm{~mm} \mathrm{MgCl}_{2}$, and $1 \mathrm{~mm}$ EDTA, pH 7.4, was used with $3 \mathrm{~nm}$ $\left[{ }^{3} \mathrm{H}\right.$ ]raclopride (specific activity, $79.3 \mathrm{Ci} / \mathrm{mmol}$; PerkinElmer Life and Analytical Sciences). A concentration of $1 \mu \mathrm{M}$ eticlopride (SigmaAldrich) was used to determine nonspecific binding. Autoradiograms were generated after an exposure time of 2 weeks and revealed by immersion of films into D-19 developer (Kodak) and rapid fixer (Kodak). Quantification of autoradiograms was performed using computerized analysis (Image 1.43u software; Wayne Rasband, NIH, Bethesda, MD). Optical gray densities were transformed into nanocuries per milligram tissue equivalent using standard curves generated with ${ }^{3} \mathrm{H}$-microscale radioactivity standards (ARC $123 \mathrm{~A}-{ }^{3} \mathrm{H}$ standards; American Radiolabeled Chemicals).

Both the shell (AcSh) and core (AcC) regions of the NAc were analyzed, as well as four subregions of the DStr [dorsomedial (StDM), dorsolateral (StDL), ventromedial $(\mathrm{StVM})$, and ventrolateral $(\mathrm{StVL})]$, as illustrated in Figure 4, $E$ and $F$.

In situ hybridization procedure. Male mice were given injections of saline ( $n=6$ for each genotype) or $25 \mathrm{mg} / \mathrm{kg}$ cocaine (cKO, $n=4$; Ctrl, $n=5) 30$ min before being killed by cervical dislocation. This time interval was chosen because mRNA levels of both Nur77 and c-fos are high at this point (Moratalla et al., 1993; Dragunow et al., 1996). Brains were rapidly removed and frozen in isopentane at $-40^{\circ} \mathrm{C}$. Brain sections were fixed in $4 \%$ paraformaldehyde at $4^{\circ} \mathrm{C}$ for $30 \mathrm{~min}$. In situ hybridization of riboprobes with tissue sections were performed at $56-58^{\circ} \mathrm{C}$ overnight in a standard hybridization buffer (Maheux et al., 2005). Tissue sections were placed in contact with BiomaxMR (Kodak) radioactivesensitive films for 3-7 d.
Specific $\left[{ }^{35} \mathrm{~S}\right] \mathrm{UTP}$-radiolabeled cRNA probes were used. The c-fos probe was generated from a $1.8 \mathrm{~kb}$ EcoRI fragment of a full-length rat c-fos cDNA, subcloned into pBluescript SK-1, and linearized with SmaI (Tremblay et al., 1999). The Nur77 probe was prepared from a $2.4 \mathrm{~kb}$ EcoRI fragment of a full-length rat NGFI-B cDNA subcloned into a pBluescript SK-1 plasmid that was linearized with BamHI (Beaudry et al., 2000; Maheux et al., 2005). Single-stranded riboprobes were synthesized and labeled using a riboprobe kit (Promega), $\left[{ }^{35} \mathrm{~S}\right] \mathrm{UTP}$ (PerkinElmer Life and Analytical Sciences), and the RNA polymerase $\mathrm{T}_{3}$ or $\mathrm{T}_{7}$.

Levels of autoradiographic labeling on films were quantified by computerized densitometry. Digitized brain images were obtained by a CCD camera (model XC-77; Sony) equipped with a $60 \mathrm{~mm} \mathrm{f} / 2.8 \mathrm{D}$ (Nikon) magnification lens. Images were analyzed using the ImageJ $1.43 \mathrm{u}$ software (Wayne Rasband, NIH). Optical densities of autoradiograms were transformed to microcuries per gram of tissue using $\left[{ }^{14} \mathrm{C}\right]$ radioactivity standards (ARC 146A- ${ }^{14} \mathrm{C}$ standards; American Radiolabeled Chemicals). Brain areas investigated included AcSh, AcC, StDM, StDL, StVM, and StVL as well as the rostral medial (StM) and rostral lateral (StL) striatum (see Fig. 4E,F). For each animal and for all brain regions investigated, we measured mRNA levels in at least four sections. Average signals from both brain hemispheres were made.

Chronoamperometric in vivo measurement of DA release and reuptake: electrode preparation and calibration. Chronoamperometric recordings of DA were performed during $100 \mathrm{~ms}, 0$ to $+550 \mathrm{mV}$ square-wave pulses $(5 \mathrm{~Hz})$ using the Fast Analytical Sensing Technology (Quanteon) according to methodological principles described previously (Gerhardt and Burmeister, 2000). In short, single carbon fiber electrodes (30 $\mu \mathrm{m}$ outer diameter, 100-200 $\mu \mathrm{m}$ length; Quanteon) were coated with two to three layers of Nafion 5\% solution (Sigma Aldrich) before use to prevent interference from anionic compounds such as ascorbic acid. Electrodes were then tested for sensitivity to ascorbic acid $(250 \mu \mathrm{M})$ and calibrated with three accumulating concentrations of DA $(2-6 \mu \mathrm{M})$ in vitro. Electrodes displaying selectivity ratios exceeding 500:1 over ascorbic acid and linear response to DA $\left(r^{2}>0.995\right)$ were used for in vivo experiments.

In vivo experimental procedure. Experiments were performed on urethane-anesthetized $\mathrm{cKO}$ and $\mathrm{Ctrl}$ mice in both the accumbens core (AcbC; Ctrl: $n=4$ males, $n=3$ females; cKO: $n=4$ males, $n=3$ females) and DStr (Ctrl: $n=7$ males, $n=4$ females; cKO: $n=9$ males, $n=3$ females). Animals were placed in a stereotactic frame and maintained at a body temperature of $37^{\circ} \mathrm{C}$. Stereotaxic coordinates were determined according to a standard brain atlas (Franklin and Paxinos, 2008): anteroposterior, +1.1 mm from bregma; ML, $\pm 1.5 \mathrm{~mm}$; DV , $-3.2 \mathrm{~mm}$ (DStr) and $-4.9 \mathrm{~mm}(\mathrm{AcbC})$ from bone surface. The $\mathrm{Ag} / \mathrm{AgCl}$ reference electrode was placed in the cortex contralateral to and distant from the recording site. DA release was evoked by four consecutive pressure ejections of $120 \mathrm{~mm} \mathrm{KCl}$, applied locally at 10 min intervals in the AcbC and at 5 min intervals in the DStr (because of higher DA content in this region).

Data analysis. Reduction/oxidation ratios (redox ratios) were calculated at the peak of every response to confirm the identity of the analyte contributing to the electrochemical signal. DA typically displays a redox ratio of 0.7-0.9 in vivo, whereas possible interfering electrochemical species have lower redox ratios (e.g., 0 for ascorbic acid and 0.1 for 5-HT) (Gerhardt and Hoffman, 2001). To ensure that DA was the contributor to the electrochemical signal, only experiments displaying redox ratios exceeding 0.7 were included in the data analysis. The average redox ratio for the experiments presented here was 0.74 . The effects of $\mathrm{KCl}$-evoked DA release were statistically analyzed with two-way ANOVA using GraphPad Prism 5.02. The following three parameters of the electrochemical signal were examined: (1) amplitude, defined as the peak DA concentration (micromoles) from baseline; (2) $t_{\text {rise, }}$ time (seconds) between ejection and maximum peak concentration; and (3) $t_{80}$, the time (seconds) from maximum peak concentration until $80 \%$ decrease of the maximum amplitude as a measure of DA clearance (Cass et al., 1993; Hebert et al., 1996; Hoffman et al., 1998).

Statistical analysis. Results are expressed as mean \pm SEM. Group comparisons were performed using $t$ tests or, when normal distribution was not observed, the Mann-Whitney $U$ test. ANOVA was used when appropriate; data from cocaine self-administration and in situ hybridization 

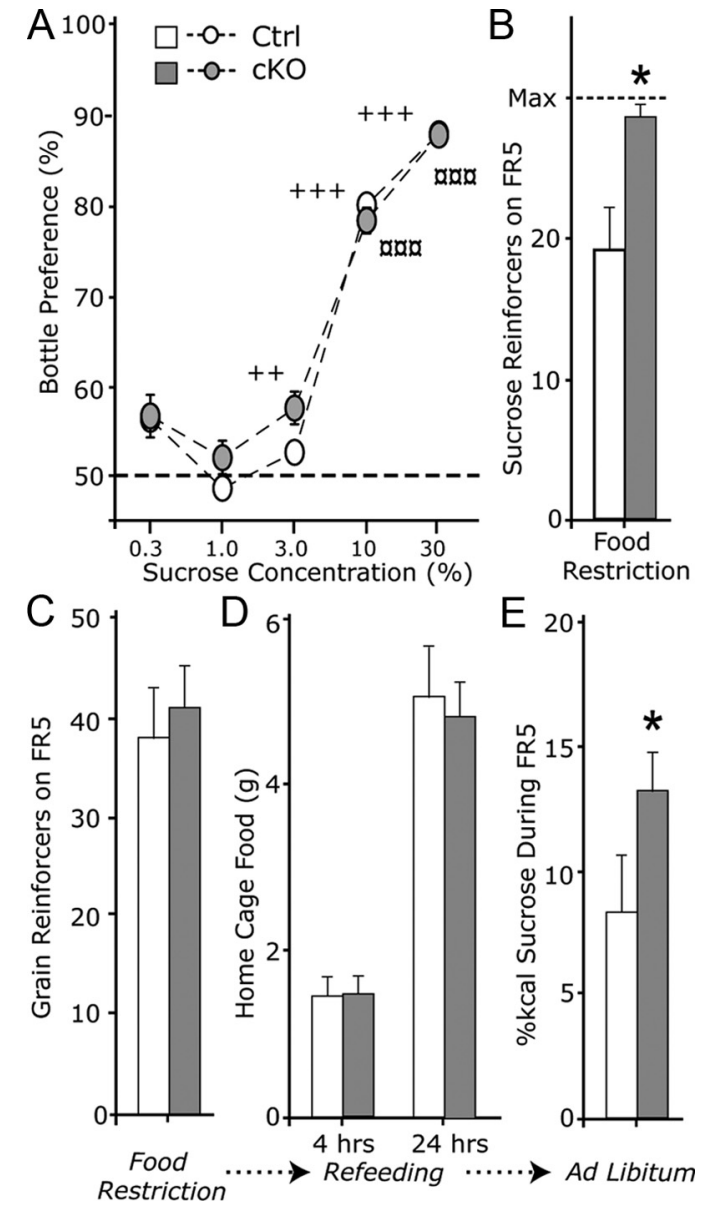

Figure 1. Self-administration of sucrose is elevated in cK0 mice. $\boldsymbol{A}$, The threshold for sucrose preference was lower in cK0 than in Ctrl mice ( $3 \%$ sucrose for $\mathrm{K} K 0$ and $10 \%$ sucrose for Ctrl mice). Significant preference in the $\mathrm{KK} 0$ group is denoted by ${ }^{++} p<0.01$ and ${ }^{+++} p<0.0001$. Significant preference in the Ctrl mice is denoted by ${ }^{\operatorname{mox}} p<0.0001$. Ctrl, $n=9$; cK0, $n=10 . \boldsymbol{B}$, Food-restricted cKO mice self-administer more sucrose reinforcers than do controls (controls, $n=6 ;(K 0, n=5)$. Max, Maximum. C, Hunger-motivated responding, i.e., self-administration of low-sucrose (grain-based) food pellets on an FR5 schedule during food restriction. $D$, Refeeding after food restriction does not differ between genotypes. $E$, Palatability-motivated feeding, i.e., \%kcal from high-sucrose pellets during ad libitum (nonrestricted) conditions. In $\mathbf{C}-\boldsymbol{E}, n=9$ controls and $n=8$ cKO were used. Group data represent mean \pm SEM. ${ }^{*} p<0.05$ versus controls.

were, when required as determined by Bartlett's $\chi^{2}$ test, $\log 10$ or square root transformed to reduce heteroscedasticity. All analyses were performed using GraphPad Prism 5.02 (GraphPad Software). Statistical significance was set at $p<0.05$.

\section{Results}

Elevated self-administration of high-sucrose, but not low-sucrose, food

To test the functional implications for VGLUT2 in DA neurons (hereafter referred to as VGLUT2/DA), we studied voluntary consumption of rewarding substances in our previously described conditional Vglut $2^{f / f ; D A T-C r e}$ mouse line (Birgner et al., 2010).

We first examined the sensitivity to sugar in nondeprived mice by providing access to sucrose solutions of a range of concentrations $(0.3-30 \%)$ in the home cage of Vglut $2^{f / f ; D A T-C r e}(\mathrm{cKO})$ and control (Fig. 1A) mice. There was no significant difference between the genotypes in preference or the amount of sucrose consumed at any of the concentrations tested (two-way repeatedmeasures ANOVA; Genotype, $p>0.05$; Genotype $\times$ Concentration interaction, $p>0.05)$. However, whereas mice of both genotypes displayed strong preference for $30 \%$ sucrose (paired $t$ test; controls: $t_{(8)}=27.35, p=0.0001$; $\left.\mathrm{cKO}: t_{(9)}=21.36, p<0.0001\right)$ and $10 \%$ sucrose (controls: $t_{(8)}=19.98, p<0.0001 ; \mathrm{cKO}: t_{(9)}=11.06$, $p<0.0001)$, cKO mice also had a significant preference for the $3.0 \%$ sucrose $\left(t_{(9)}=4.78 ; p=0.0010\right)$, at which concentration the control mice consumed equal amounts of sucrose and water $(p>0.05)$. No preference over water was observed at concentrations of 1 and $0.3 \%$ sucrose $(p>0.05)$. The thresholds for sucrose preference were thus $3 \%$ in $\mathrm{cKO}$ mice and $10 \%$ in control mice.

Next, mice were analyzed for self-administration of sucrose pellets in the operant setting. To determine whether the acquisition of an operant response task in the $\mathrm{cKO}$ mice was impaired, mice were first trained to nosepoke on an FR1 schedule for sucrose pellets during mild food restriction. The rate of acquisition across all self-administration experiments was not significantly different between $\mathrm{cKO}(5.4 \pm 0.3 \mathrm{~d}$ to criterion) and littermate control $(6.2 \pm 0.4 \mathrm{~d}$ to criterion; Mann-Whitney $U$ test, $p=$ 0.057; controls, $n=23$; cKO, $n=22$ ) mice. However, cKO mice self-administered more sucrose during FR5 than did the control mice (Mann-Whitney $U$ test, $p=0.030$; Fig. $1 B$ ). There was no change in the number of nosepokes in the inactive aperture; the lack of change in the percentage of error thus suggests that goal-directed responses were selectively facilitated in the $\mathrm{CKO}$ mice (data not shown).

Because a higher self-administration of food pellets in the cKO mice could indicate a generalized increase in consummatory responding for any food or reward, a second set of mice was analyzed for nosepoke response for low-sucrose grainbased pellets during food restriction (hunger-driven feeding) and for response for high-sucrose pellets during nonrestricted conditions (sucrose reward-driven feeding). No differences were observed when mice responded for low-sucrose pellets during food restriction (Mann-Whitney $U$ test, $p>0.10$ ) (Fig. 1C). Accordingly, neither the baseline chow intake (data not shown) nor the refeeding after food restriction differed between the genotypes (Fig. 1D). However, when the mice had free home cage access to standard rodent chow, cKO mice consumed a higher percentage of their total kcal intake from the high-sucrose pellets than did the control mice (Mann-Whitney $U$ test, $p=0.0464$ ) (Fig. $1 E$ ). Inactive responding was low during all reinforcer/ schedule conditions and did not differ between the two genotypes (data not shown).

By allowing different schedules of reinforcement, the operant self-administration model infers a flexibility that allows the investigation of both consummatory (low fixed ratios) and appetitive responses (progressive ratio), which are two distinct traits in mice caused by a number of factors, including differences in postoral satiety (Sclafani, 2006). Motivation for food reward was thus analyzed by means of the PR schedule. No alterations were detected in either hunger-driven (cKO reached $13.5 \pm 1.0$ reinforcements; controls, $12.9 \pm 1.4$; Mann-Whitney $U$ test, $p>0.10$ ) or palatability-driven (number of reinforcements for Vglut $2^{f / f ; D A T-C r e}$ mice, $11.0 \pm 1.20$; controls, $8.68 \pm 1.45$; Mann-Whitney $U$ test, $p>0.10$ ) appetitive response for food on the PR schedule. Together, these results show that loss of VGLUT2/DA leads to increased palatability-driven feeding on a low fixed ratio. In contrast, the targeted deletion of VGLUT2 had no impact on the appetitive dimension of food reward, because PR responding motivated by either palatability or hunger was similar between $\mathrm{CKO}$ and control mice. 


\section{Increased operant responding for cocaine and cocaine-paired cues}

We next sought to determine whether VGLUT2/DA plays a role also in the operant self-administration of cocaine. This paradigm displays high face and predictive validity for cocaine abuse in humans (Schuster and Thompson, 1969; Collins et al., 1984; Sanchis-Segura and Spanagel, 2006). Mice were surgically implanted with indwelling intravenous catheters and subsequently allowed to nosepoke for cocaine over a wide range of concentrations $(0.0625,0.125,0.25,0.5,1.0 \mathrm{mg} / \mathrm{kg}$ per infusion) on an FR4 schedule. There was a significant interaction between dose and genotype (two-way repeated-measures ANOVA; Dose: $F_{(4,12)}=$ 9.88, $p<0.0001$; Genotype: $F_{(1,12)}=1.8, p>0.10$; Dose $\times$ Genotype interaction: $\left.F_{(4,48)}=2.74, p=0.039\right)$, explained by the fact that the Vglut $2^{f / f ; D A T-C r e}$ knock-outs displayed a significantly elevated active nosepoke response at the lowest concentration of cocaine (Bonferroni posttest, $p=0.034$ ) with a trend toward increased active nosepokes at the doses of $0.125,0.25$, and 0.5 $\mathrm{mg} / \mathrm{kg}$ per infusion. At the highest dose, no difference was detected between the genotypes (Fig. 2A). Accordingly, whereas Vglut $2^{f / f ; D A T-C r e}$ mice self-administered more cocaine than did controls at the lowest $(0.0625 \mathrm{mg} / \mathrm{kg}$ infusion $)$ dose, no dissociation between genotypes was observed at the highest doses (two-way repeated-measures ANOVA; Dose $\times$ Genotype interaction: $F_{(4,48)}=3.63, p=0.012$; Bonferroni posttest, $p=0.037)$ (Fig. $2 B$ ).

Exposure to drug-associated memories is thought to enhance the vulnerability to relapse to drug use. Models of relapse to cocaine-seeking and -taking behavior in response to drugassociated cues are thus highly relevant for the study of addiction (Shaham et al., 2003). To investigate the role of VGLUT2/DA in cocaine seeking, all mice first responded at $0.75 \mathrm{mg} / \mathrm{kg}$ per infusion to ensure high response rates. After $21 \mathrm{~d}$ of forced abstinence, mice were allowed to respond for the presentation of visual and auditory cocaine-associated cues in the absence of cocaine delivery. Notably, the Vglut $2^{f / f ; D A T-C r e}$ mice showed a $76 \%$ increase in their cocaine-seeking response compared with the control mice (two-way repeated-measures ANOVA; Condition: $F_{(1,9)}=7.82, p=0.021$; Genotype: $F_{(1,9)}=7.65, p=0.022$; Condition $\times$ Genotype interaction: $\left.F_{(1,9)}=7.31, p=0.024\right)$ (Fig. $2 C)$. No difference was noted in responses at the inactive nosepoke aperture (data not shown). These analyses show that $\mathrm{CKO}$ mice displayed both increased consumption of cocaine at low dose and increased cocaine seeking in response to drug-associated cues. Together, these results suggest that the loss of VGLUT2/DA leads to an addiction-prone phenotype.

\section{Differentially altered $D_{1}$ and $D_{2}$ binding site levels in ventral and dorsal striatum}

The high responsiveness to reward was suggestive of the occurrence of neuroadaptations. To determine whether loss of VGLUT2/DA was associated with changes in the number of DA receptor binding sites, we used autoradiography to examine the specific binding of tritiated $\mathrm{SCH} 23390$ for $\mathrm{D}_{1} \mathrm{R}$ (Fig. $3 A$ ) and raclopride for $\mathrm{D}_{2} \mathrm{R}$ (Fig. $3 B$ ) in the striatum of $\mathrm{Vglut} 2^{\mathrm{f} / f ; D A T-C r e}$ and control mice. Six striatal subregions (Fig. 4E,F) were analyzed for $D_{1} R$ and $D_{2} R$ binding site levels. The number of $D_{1} R$ receptor binding sites did not differ between $\mathrm{cKO}$ and control mice in the AcSh, AcC, or StDM $(p>0.05)$. However, a significant increase was noted in cKO mice in the StDL $\left(t_{(13)}=2.166\right.$; $p=0.0495), \operatorname{StVM}\left(t_{(13)}=4.106 ; p=0.0012\right)$, and StVL $\left(t_{(12)}=\right.$ $2.594 ; p=0.0235)$. In contrast, tritiated raclopride binding, denoting $\mathrm{D}_{2} \mathrm{R}$ levels, was significantly increased in the shell of the
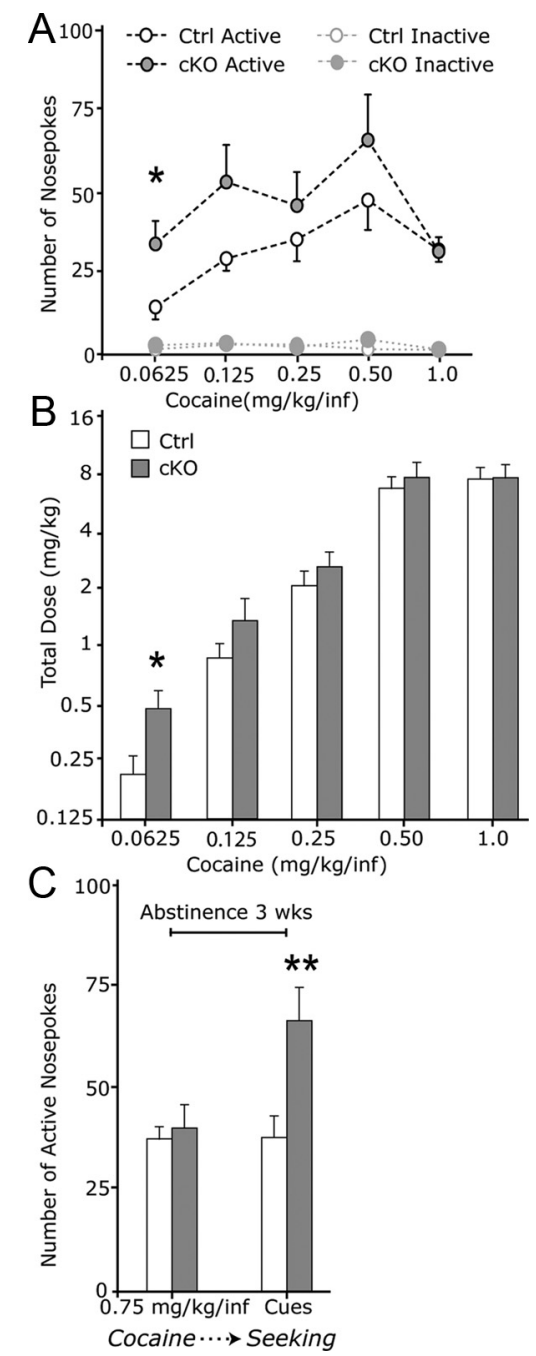

Figure 2. Elevated operant responding for low-dose cocaine and drug-paired cues during extinction in cKO mice. $\boldsymbol{A}$, Nosepoke response of food-trained mice implanted with indwelling intravenous catheters and allowed to nosepoke for cocaine infusions (controls, $n=7 ; \mathrm{ckO}, n=$ 7). $\boldsymbol{B}$, Total dose self-administered at the different cocaine concentrations in $\boldsymbol{A}$. C, Cocaineseeking, i.e., responding for light and sound cues previously associated with cocaine in the absence of the drug, of mice from $\boldsymbol{A}$ that had been responding for $0.75 \mathrm{mg} / \mathrm{kg}$ per infusion (inf) and subsequently subjected to $21 \mathrm{~d}$ of forced cocaine abstinence (controls, $n=6 ; \mathrm{ck} 0, n=5$ ). Group data represent mean \pm SEM. ${ }^{*} p<0.05 ;{ }^{* *} p<0.01$ versus $\mathrm{Ctrl}$.

NAc $\left(t_{(10)}=2.246 ; p=0.0485\right)$ in $\mathrm{cKO}$ compared with control mice, whereas the core region showed a strong trend $(p=0.05)$ toward increased binding. No apparent change in $\mathrm{D}_{2} \mathrm{R}$ binding was detected in the dorsostriatal areas. These findings show a subregional upregulation of DA receptors in the striatum of $\mathrm{cKO}$, a neuroadaptation that could mediate the increased responsiveness to reward.

\section{Increased basal levels of Nur77 and c-fos mRNA in the striatum}

The observed alteration in binding site availability of $D_{1} R$ and $\mathrm{D}_{2} \mathrm{R}$ prompted us to further analyze postsynaptic responsiveness in the striatum of the $\mathrm{cKO}$ mice. The orphan nuclear receptor Nur77 participates in psychostimulant-induced locomotor activity (Bourhis et al., 2009), whereas the zinc finger transcription factors of the Fos family are involved in food-reinforcement and cocaine-seeking behaviors (Nestler et al., 2001; Olausson et al., 2006). Both families of transcription factors are modulated by 

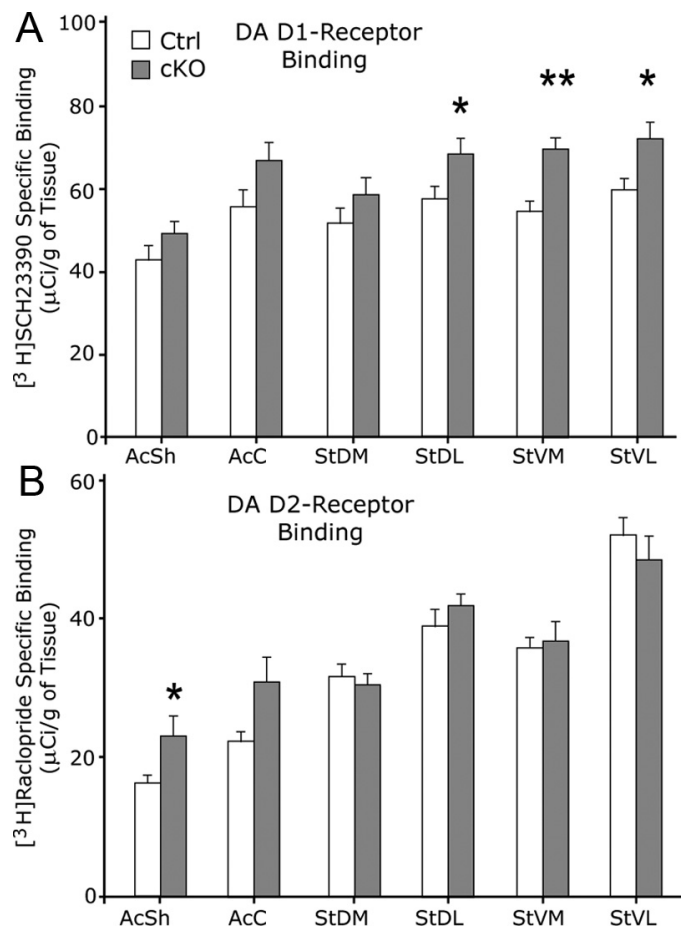

Figure 3. Dopamine receptor binding is altered in $C K 0$ mice. $A, D_{1} R$ binding sites in $c K 0(n=$ $6)$ and control $(n=9)$ mice were measured by auroradiography using [ $\left.{ }^{3} \mathrm{H}\right] \mathrm{SCH}-23390, B_{1} \mathrm{D}_{2} \mathrm{R}$ binding sites were measured by autoradiography using $\left[{ }^{3} \mathrm{H}\right]$ raclopride binding on sections adjacent to those used in $A$. DA receptor binding site levels were evaluated in the AcSh and AcC and in striatal subterritories (StDM, StDL, StVM, StVL) in Ctrl and CKO mice. Group data represent mean \pm SEM. ${ }^{*} p<0.05$ and ${ }^{* *} p<0.01$ versus $C$ trl.

acute and repeated psychostimulant treatments and participate in neurochemical postsynaptic responsiveness to drugs of abuse. We analyzed the same six striatal subregions (Fig. $4 E, F$ ) for mRNA expression levels of the IEGs Nur77 and c-fos after acute cocaine or saline treatment. A strong upregulation of Nur77 mRNA was seen after cocaine challenge in the control mice at all ventral and dorsal striatal levels examined $[p<0.05$ vs saline group by Tukey's multiple comparison test, following one-way ANOVA in the $\operatorname{AcSh}\left(F_{(3,19)}=4.509 ; p=0.0178\right), \operatorname{AcC}\left(F_{(3,19)}=\right.$ $4.723 ; p=0.0100), \operatorname{StM}\left(F_{(3,19)}=7.562 ; p=0.0023\right), \operatorname{StL}\left(F_{(3,19)}=\right.$ $11.58 ; p=0.0003), \operatorname{StDM}\left(F_{(3,19)}=4.291 ; p=0.0147\right)$, StDL $\left(F_{(3,19)}=13.25 ; p<0.0001\right), \operatorname{StVM}\left(F_{(3,19)}=3.412 ; p=0.0337\right)$, and $\left.\operatorname{StVL}\left(F_{(3,19)}=10.65 ; p=0.0004\right)\right]$ (Fig. 4). Interestingly, saline-treated CKO mice displayed elevated basal Nur77 mRNA levels in the AcC (Fig. 4A,E), StM, and StL (Fig. 4B,E). Although not statistically significant, a similar trend of higher basal Nur77 mRNA levels was also detected in the StDM, StDL (Fig. 4C,E), and StVM (Fig. 4D,E). Because of the elevated baseline, cocaine injections did not cause any further increase in Nur77 mRNA expression after the cocaine challenge in any region analyzed in Vglut $2^{f / f ; D A T-C r e}$ mice. In the StVL, the cocaine-stimulated induction of Nur77 mRNA was significantly lower in Vglut $2^{f / f ; D A T-C r e}$ mice than in control mice $(p<0.05)$ (Fig. $4 D, E)$.

The analysis of c-fos mRNA expression levels in the sections adjacent to the ones analyzed for Nur77 expression also showed a strong basal upregulation that abolished the cocaine-induced effect in all of the brain areas studied (data not shown). Together, these analyses show an upregulation of Nur77 and c-fos to the same high levels as after cocaine stimulation in cKO mice, further confirming the induction of adaptive changes in absence of VGLUT2/DA.

\section{Perturbation of in vivo DA release and reuptake in the NAc and DStr}

Based on the observation that Vglut $2^{f / f D A T-C r e}$ knock-out mice self-administer more high-sugar food and cocaine, and show increased cue-induced cocaine seeking after abstinence, it was relevant to analyze DA release in both the NAc and DStr. For this, we used in vivo chronoamperometry and a repeated challenge paradigm in both the NAc and DStr; the first stimulation allowed analysis of the basal capacity of the system, whereas the subsequent three stimulations provided an estimation of the capacity for recovery. Nafion-coated electrodes were surgically implanted in the striatum of urethane-anesthetized mice as illustrated in Figure $5 A$. Only electrodes with a ratio of reduction/oxidation signals above 0.7 (average, 0.74), which ensures a selectivity for DA, were used (Fig. 5B). DA release and reuptake were analyzed after four consecutive pressure ejections of $120 \mathrm{~mm} \mathrm{KCl}$, which results in a potent but local depolarization. In the NAc of cKO mice, this ejection paradigm resulted in significantly lower overall amplitude of DA release than in controls (two-way ANOVA; Genotype: $F_{(1,48)}=12.91, p=0.0008$ ) (Fig. $5 C$ ). Whereas the time to peak, $t_{\text {rise }}$, was similar between genotypes $(p>0.05)$ (Fig. $5 D$ ), the clearance period, $t_{80}$, defined as the time from maximal amplitude to $80 \%$ decline, was significantly increased in $\mathrm{cKO}$ mice compared with the controls (two-way ANOVA; Genotype: $F_{(1,59)}=4.191, p=0.0451$ ) (Fig. $5 E$ ). No interaction was observed in amplitude, $t_{\text {rise }}$, or $t_{80}$ after all four ejections. After peak analysis of DA release kinetics after the first ejection, a rightshifted curve was observed in the cKO mice, with a smaller amplitude and a 2.8 times longer $t_{80}$, amounting to an overall equivalent area under the curve in the $\mathrm{CKO}$ and control mice $(p>0.05)$ (Fig. 5F).

In the DStr, repeated potassium-evoked depolarization resulted in significantly lower peak DA amplitude in the cKO mice than in the controls (two-way ANOVA; Genotype: $F_{(1,156)}=6.91$, $p=0.0094$ ) (Fig. 5G). There was a significant reduction in the $t_{\text {rise }}$ in the DStr of cKO mice compared with the control mice (twoway ANOVA; Genotype: $\left.F_{(1,165)}=8.73, p=0.0025\right)($ Fig. $5 H)$, whereas $t_{80}$ was similar between the two genotypes $(p>0.05)$ (Fig. 5I). Although no interactions were observed with regard to these parameters, we found a significant Genotype $\times$ Ejection interaction with regard to area under the curve in the DStr (twoway ANOVA; Genotype: $F_{(1,106)}=7.93, p=0.0058$; Genotype $\times$ Ejection interaction: $\left.F_{(9,106)}=5.47, p<0.0001\right)$, explained by the fact that the first ejection resulted in a response with smaller overall area under the curve in the $\mathrm{KKO}$ mice compared with the controls (post hoc test, $p=0.0485$ ) (Fig. 5J). Together, these results show that DA release after depolarization is decreased in both the NAc and DStr of the cKO mice. Both basal capacity to release DA, as demonstrated in response to the first stimulation, and release after repeated stimulation were less in the two striatal areas in the cKO mice. Because neither the NAc nor the DStr displayed a statistically significant interaction after the repeated challenge in the $\mathrm{cKO}$ mice versus control mice, the capacity to recover after challenge is similar in the two genotypes.

\section{Discussion}

The present study reveals abnormalities in reward behavior and striatal function of significance for drug addiction and for overeating in obesity in mice lacking VGLUT2 specifically in DA neurons. 

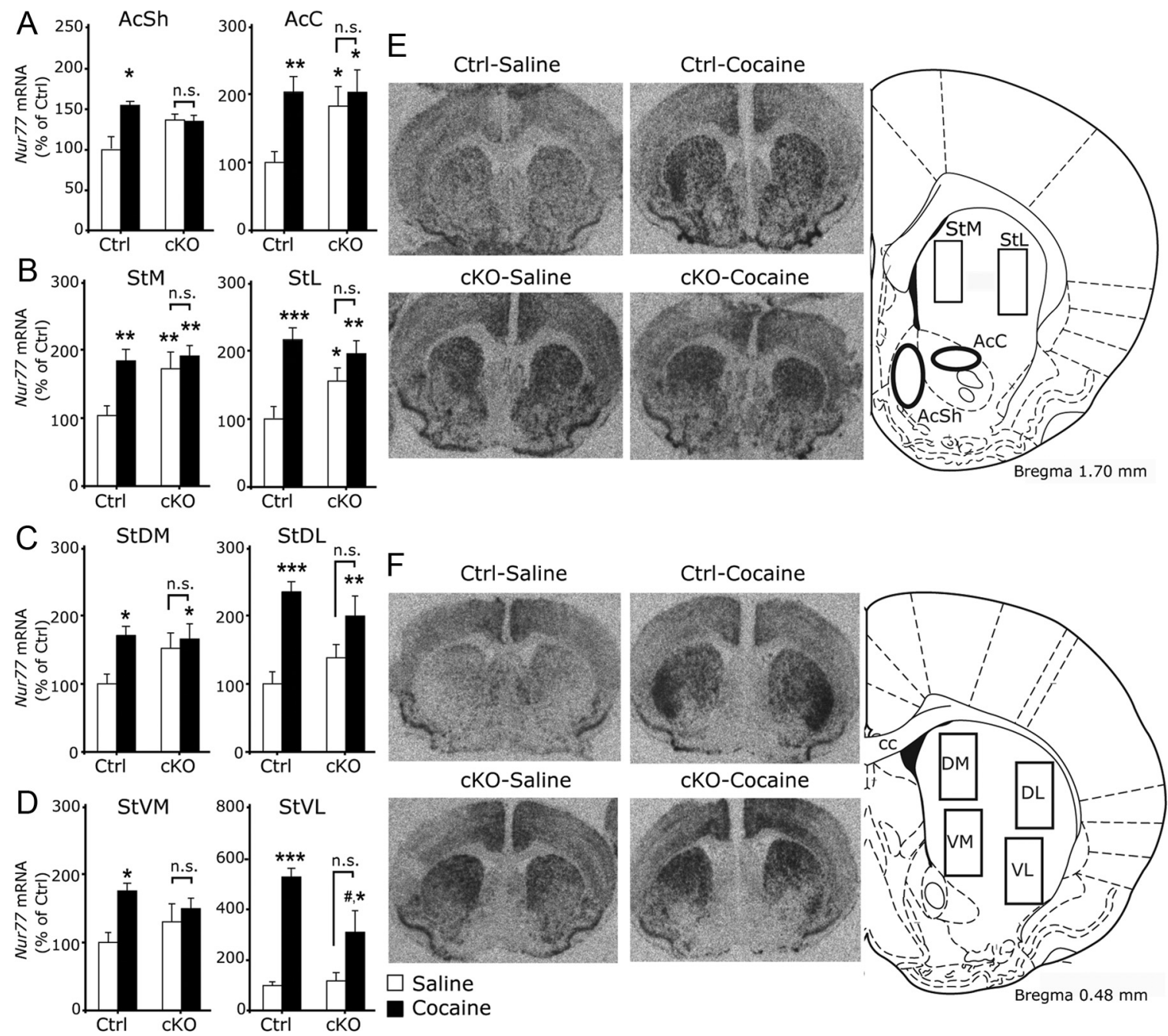

Figure 4. High expression of Nur77 under baseline conditions in cKO mice. $A-D$, Quantitative in situ hybridization of Nur77 mRNA levels in Ctrl and cK0 mice treated with saline (Ctrl, $n=6$; $c K 0$, $n=7$ ) or cocaine (Ctrl, $n=5 ; \mathrm{cKO}, n=4)$. $\boldsymbol{A}$, Levels of Nur77 mRNA in AcSh and AcC (bregma, $1.70 \mathrm{~mm})$. B, Nur77 mRNA levels in medial (StM) and lateral (StL) rostral striatum (bregma, $1.70 \mathrm{~mm}$ ). C, Nur77 transcript levels in the caudodorsal striatum (bregma, $0.48 \mathrm{~mm}$ ). D, Nur77 levels in the caudoventral striatum (bregma, 0.48 ). $\boldsymbol{E}, \boldsymbol{F}$, Representative autoradiograms of Nur77 mRNA in situ hybridization signals in the rostral striatal area ( $\boldsymbol{E}$; bregma, $1.70 \mathrm{~mm}$ ) and in the caudal striatal area $(\boldsymbol{F}$; bregma, $0.48 \mathrm{~mm}$ ) with schematic illustrations to the right showing location of the analyzed regions. Group data represent mean \pm SEM expressed as percentage of $C \operatorname{trl}$ (saline). ${ }^{*} p<0.05,{ }^{* *} p<0.01$, and ${ }^{* * *} p<0.001$ versus Ctrl saline group; ${ }^{\#} p<0.05$ versus Ctrl cocaine group. cc, Corpus callosum.

\section{Loss of VGLUT2 in DA neurons leads to elevated consumption of reward}

When cKO and littermate control mice were allowed to respond for food or cocaine in the operant setting, the cKO mice displayed increased self-administration of both high-sucrose food and cocaine compared with controls. Whereas performance at the higher cocaine doses did not differ between genotypes, Vglut2 $2^{f f-D A T-C r e}$ mice self-administered significantly more cocaine at the lowest dose $(0.0625 \mathrm{mg} / \mathrm{kg}$ per infusion), which failed to maintain stable responding in control animals. This finding indicates an elevated responsiveness in $\mathrm{cKO}$ mice to the rewarding effect of cocaine. Consistently, elevated operant responding maintained by sucrose was also observed in the $\mathrm{CKO}$ mice. In a home cage bottle preference test, cKO mice displayed a lower threshold for sucrose preference, indicative of elevated sucrose sensitivity. The mesolimbic DA system is repeatedly activated after food exposure only if the food is novel or during restricted access to palatable food (Bassareo and Di Chiara, 1997, 1999; Rada et al., 2005). Because we did not observe genotype differences in hunger-driven feeding, but found that $\mathrm{cKO}$ mice displayed elevated consumption of su- crose compared with controls, these observations show that VGLUT2/DA has an important role in palatability-stimulated feeding in addition to cocaine self-administration.

\section{Dopamine dysfunction in both ventral and dorsal striatum}

$\mathrm{KCl}$-evoked DA release was decreased in both the NAc and DStr of the cKO mice. Recordings in the living mouse brain, as performed in the current study, offer the advantage over slice preparations that the circuitry dynamics remain intact. Moreover, because $\mathrm{KCl}$-induced stimulation gives a significantly more potent DA release than occurs under physiological conditions, it allows the detection of the full capacity of the system to release DA. These considerations may explain why we detected differences in both the DStr and NAc, whereas reduced DA release was previously noted only in the NAc in a study using single action potential stimulation in slice preparations from another Vglut $2^{f f f D A T-C r e}$ mouse line (Hnasko et al., 2010). The unveiled lower DA release levels in both the NAc and the DStr are in tune with previous results of blunted psychomotor response in Vglut2 $2^{f f ;}$ DAT-Cre $c K O$ mice to acute stimulation by 

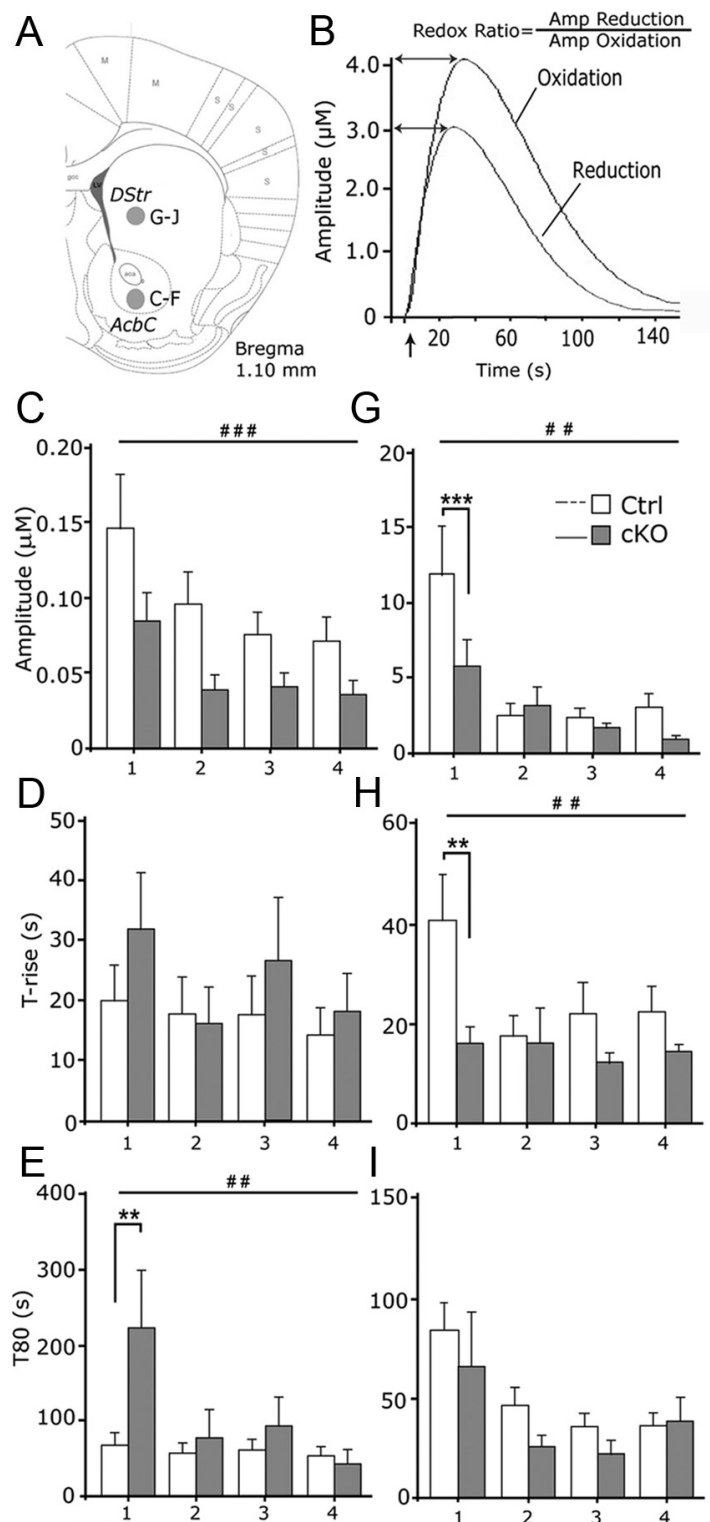$$
\mathrm{F}
$$

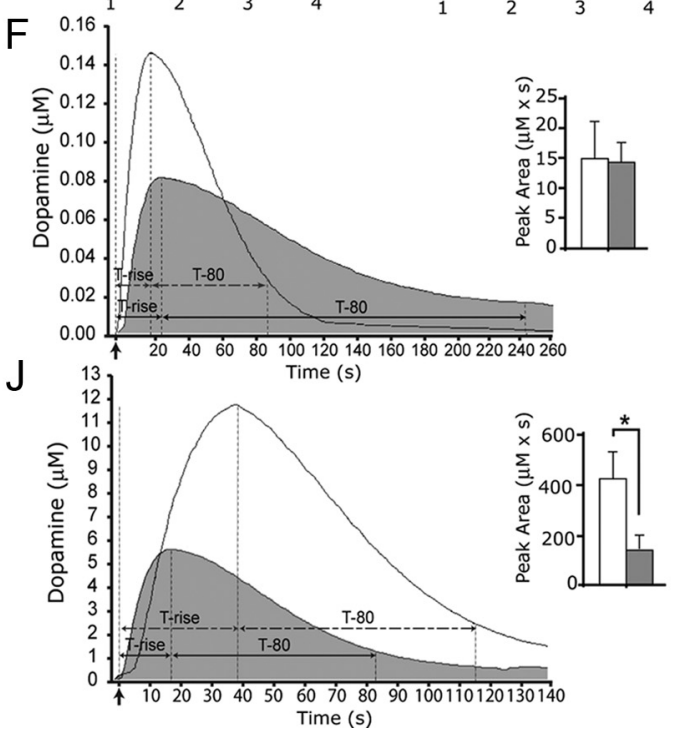

Figure 5. Decreased DA release in ventral and dorsal striatum of cKO mice. $A$, Graphical illustration of placement of DA-selective electrode for in vivo amperometric measurements in amphetamine (Birgner et al., 2010) and cocaine (Hnasko et al., 2010), as psychomotor effects are mediated by DA release in both of these regions (Giros et al., 1996).

cKO mice not only responded more strongly than controls when allowed to self-administer sucrose and cocaine but also when, during the cocaine-seeking session, they were presented with the visual and auditory cues associated with cocaine reward. Although the reinforcing effect of reward consumption is mediated mainly via the NAc, cocaine-associated seeking has been shown also to involve the DStr (Vanderschuren et al., 2005; See et al., 2007). Thus, whereas the DStr is not engaged in mediating reinforcing effects of the drugs during early exposure, DA signaling in this structure is recruited during the transition toward compulsive, uncontrolled, chronic use (Porrino et al., 2004; Everitt and Robbins, 2005). Therefore, the altered DA release within the DStr is of particular interest for the enhancement of cocaine-seeking behavior in the Vglut $2^{f f ; D A T-C r e}$ mice.

\section{Sensitized phenotype caused by neuroadaptations increases responsiveness to reward}

Palatable food and drugs of abuse, as well as drug-paired cues, stimulate DA release (Di Chiara and Imperato, 1988; Bassareo and Di Chiara, 1999), and, moreover, human imaging studies indicate that the amount of DA released is correlated to the hedonic impact of psychostimulants (Drevets et al., 2001) and palatable food (Small et al., 2003). In light of this, our findings of reduced striatal DA concomitant with elevated reward-seeking and -taking behavior may seem contraintuitive. How can our results be explained?

First, we observed an upregulation of D1R and D2R binding sites in the striata of cKO mice. Both of these receptor types previously have been shown to mediate behavioral and biochemical effects of acute and repeated cocaine administration (Xu et al., 1994; Caine et al., 2002; Caine et al., 2007; Welter et al., 2007). D1R mediates reward learning in response to palatable food (Hikida et al., 2010), and targeted loss of D1R decreases operant responding for sucrose (El-Ghundi et al., 2003). Sucrose preference is reduced by D2R antagonism (Hsiao and Smith, 1995), whereas upregulated D2R levels in the NAc have been reported in some rodent studies of repeated cocaine administration (Peris et al., 1990; Maggos et al., 1998; Briand et al., 2008). The elevated D1R and D2R levels observed in this study could thus lead to the increased responsiveness to palatable food and cocaine. Furthermore, the basal expression level of DA-regulated IEGs Nur77 and $c$-fos was increased in both the NAc and DStr of the cKO mice in such a potent manner that cocaine could not further increase these levels. Together, these data suggest that loss of VGLUT2/DA has produced a potent, sensitized neurobiolog-

$\leftarrow$

DStr and AcbC (bregma, $1.10 \mathrm{~mm}$ ). $\boldsymbol{B}$, Representative DA trace illustrating the calculation of redox ratio for each peak. $C, G, D A$ amplitude, defined as the peak DA concentration (micromoles) from baseline in $A c b C$ and DStr in response to four consecutive ejections of $120 \mathrm{~mm} \mathrm{KCl}$. $\boldsymbol{D}, \boldsymbol{H}, t_{\text {rise, }}$ defined as time (seconds) between ejection and peak maximum $(\boldsymbol{F}, \boldsymbol{J})$, in $\mathrm{Acb} C$ and $D S$ tr for the four releases of DA. $E, I, t_{80}$ defined as the time (seconds) from peak amplitude until the signal reached $20 \%$ of the peak amplitude $(\boldsymbol{F}, \boldsymbol{J})$, in AcbC and DStr for the four $\mathrm{KCl}$-evoked releases of DA. $\boldsymbol{F}, \boldsymbol{J}$, Schematic illustrations of the first post-KCl ejection recordings of DA, based on graph values, for $\operatorname{AcbC}(\boldsymbol{F})$ and $D S \operatorname{tr}(\boldsymbol{J})$. Insets show analysis of peak area, defined as area under curve. Four consecutive $\mathrm{KCl}$ ejections (numbered $1-4$ on $x$-axes) were used, spaced by 5 $\min$ for DStr and $10 \mathrm{~min}$ for $\mathrm{AcbC}$. AcbC data are from $n=7 \mathrm{Ctrl}$ and $n=7 \mathrm{cKO}$ mice. DStr data are from $n=11$ controls and $n=12 \mathrm{cKO}$ mice. Group data represent mean \pm SEM. Significant main genotype effects observed by ANOVA analysis are illustrated by ${ }^{\#} p<0.01$ and ${ }^{\# \#} p<$ 0.001 ; differences by post hoc test are shown by ${ }^{*} p<0.05,{ }^{* *} p<0.01$, and ${ }^{* * *} p<0.001$. 
ical phenotype, which may mimic the biochemical changes induced by repeated exposure to psychostimulants (Peris et al., 1990). These adaptations possibly occur in response to the reduced DA levels and may contribute to the signs of increased reward responsiveness reported here, including elevated selfadministration of low-dose cocaine and reduced threshold for sucrose preference.

Second, an alternative explanation relates directly to the reduced DA release. Studies of cocaine self-administration, electrical brain self-stimulation, and compulsive intake of palatable food after genetic or pharmacological manipulations of the DA system previously have shown a negative correlation between reward taking and DA signaling (Seeger et al., 1981; Caine et al., 2002; Johnson and Kenny, 2010). Moreover, human studies suggest that cocaine addicts exhibit decreased DA levels in the striatum in response to drug reward (Volkow et al., 1997). Thus, it has been speculated that DA hypofunction stimulates drug taking to normalize DA levels (Blum et al., 1996; Koob and Le Moal, 2001). Similar effects could possibly contribute to the elevated reward taking also in Vglut2 $2^{f f ; \text { DAT-Cre }}$ mice. However, such reward deficiency is typically associated with reduced DA receptor binding (Volkow et al., 2008; Johnson and Kenny, 2010) and a general (nondose-dependent) increase in self-administration (Ahmed and Koob, 1998), not with elevated receptor levels and increased sensitivity to reward as observed here. Thus, although DA hypofunction may be correlated to the behavior of the cKO, we argue that a sensitized phenotype is a more plausible explanation for this correlation than reward deficiency mechanisms.

\section{Spatiotemporal regulation of VGLUT2 of putative relevance to the observed reward dysfunction}

Both the behavioral and biochemical findings of the present study suggest a functional role for VGLUT2 in DA neurons of both the substantia nigra pars compacta $(\mathrm{SNc})$, which gives rise to the main projection to the DStr, and the VTA, which projects most densely to the NAc and, to a lesser degree, to the DStr. Studies examining the expression of Vglut2 in midbrain DA neurons have shown this cophenotype to be present in both the SNc and VTA from early development to adult stages (Dal Bo et al., 2004; Mendez et al., 2008; Birgner et al., 2010). However, it has been emphasized that the cophenotype is more abundant in VTA than SNc neurons, at least in the postnatal rat (Dal Bo et al., 2004, 2008; Kawano et al., 2006; Mendez et al., 2008; Yamaguchi et al., 2011). Moreover, whereas VGLUT2 protein has been detected in DA axon terminals (tyrosine hydroxylase-positive) of both the NAc and DStr in the preadolescent rat, it could no longer be observed in the adult (Bérubé-Carrière et al., 2009; Moss et al., 2011). This spatiotemporal regulation of Vglut2 expression has been suggested to mediate neuronal survival (Dal Bo et al., 2008) and formation and maintenance of synaptic contacts (BérubéCarrière et al., 2009) and could be of importance for the reward dysfunction at the behavioral and biochemical levels observed here in the cKO mice. Furthermore, VGLUT2 was recently shown to coprecipitate with VMAT2 in vesicular preparations from the NAc of young mice (Hnasko et al., 2010), and it was suggested in the same study that VGLUT2 may facilitate DA packaging in a similar manner as VGLUT3 promotes packaging of acetylcholine, by a process referred to as vesicular synergy (Gras et al., 2008). Although this process remains to be confirmed in DA neurons, loss of VGLUT2 could lead to lower DA release because of less efficient packaging.

It was recently demonstrated that glutamate is released by the mesoaccumbal DA projection in response to electrical stimuli mimicking the activation pattern elicited by primary reward and reward-predicting cues (Tecuapetla et al., 2010). Therefore, it is intriguing to speculate that absence of VGLUT2-mediated glutamate corelease from DA neurons, and the ensuing loss of excitatory drive, could have a direct impact on reward-dependent changes in the excitability and firing of medium spiny neurons of the striatum (Wolf, 2010). Given the strong implication for addictive-like behavior, it is crucial that the mechanisms by which VGLUT2 in DA neurons impacts on the reward system be addressed shortly.

We found a physiological role for VGLUT2/DA in the reward system by contributing to reward consumption and rewardassociated learning. We report strong evidence suggesting that loss of VGLUT2 leads to an addiction-like phenotype substantiated by synaptic neuroadaptations in both ventral and dorsal striatum. These findings indicate that alterations in the glutamate-DA cophenotype could be at the origin of reward-related disorders and that further characterization of this cophenotype might contribute to the development of new strategies for treatment of these disorders.

\section{References}

Ahmed SH, Koob GF (1998) Transition from moderate to excessive drug intake: change in hedonic set point. Science 282:298-300.

Bassareo V, Di Chiara G (1997) Differential influence of associative and nonassociative learning mechanisms on the responsiveness of prefrontal and accumbal dopamine transmission to food stimuli in rats fed ad libitum. J Neurosci 17:851-861.

Bassareo V, Di Chiara G (1999) Modulation of feeding-induced activation of mesolimbic dopamine transmission by appetitive stimuli and its relation to motivational state. Eur J Neurosci 11:4389-4397.

Beaudry G, Langlois MC, Weppe I, Rouillard C, Levesque D (2000) Contrasting patterns and cellular specificity of transcriptional regulation of the nuclear receptor nerve growth factor-inducible B by haloperidol and clozapine in the rat forebrain. J Neurochem 75:1694-1702.

Bérubé-Carrière N, Riad M, Dal Bo G, Levesque D, Trudeau LE, Descarries L (2009) The dual dopamine-glutamate phenotype of growing mesencephalic neurons regresses in mature rat brain. J Comp Neurol 517:873-891.

Birgner C, Nordenankar K, Lundblad M, Mendez JA, Smith C, le Greves M, Galter D, Olson L, Fredriksson A, Trudeau LE, Kullander K, WallenMackenzie A (2010) VGLUT2 in dopamine neurons is required for psychostimulant-induced behavioral activation. Proc Natl Acad Sci U S A 107:389-394.

Blum K, Sheridan PJ, Wood RC, Braverman ER, Chen TJ, Cull JG, Comings DE (1996) The D2 dopamine receptor gene as a determinant of reward deficiency syndrome. J R Soc Med 89:396-400.

Bourhis E, Maheux J, Paquet B, Kagechika H, Shudo K, Rompre PP, Rouillard C, Levesque D (2009) The transcription factors Nur77 and retinoid X receptors participate in amphetamine-induced locomotor activities. Psychopharmacology (Berl) 202:635-648.

Briand LA, Flagel SB, Seeman P, Robinson TE (2008) Cocaine selfadministration produces a persistent increase in dopamine D2 High receptors. Eur Neuropsychopharmacol 18:551-556.

Caine SB, Negus SS, Mello NK, Patel S, Bristow L, Kulagowski J, Vallone D, Saiardi A, Borrelli E (2002) Role of dopamine D2-like receptors in cocaine self-administration: studies with D2 receptor mutant mice and novel D2 receptor antagonists. J Neurosci 22:2977-2988.

Caine SB, Thomsen M, Gabriel KI, Berkowitz JS, Gold LH, Koob GF, Tonegawa S, Zhang J, Xu M (2007) Lack of self-administration of cocaine in dopamine D1 receptor knock-out mice. J Neurosci 27:13140-13150.

Cass WA, Zahniser NR, Flach KA, Gerhardt GA (1993) Clearance of exogenous dopamine in rat dorsal striatum and nucleus accumbens: role of metabolism and effects of locally applied uptake inhibitors. J Neurochem 61:2269-2278.

Collins RJ, Weeks JR, Cooper MM, Good PI, Russell RR (1984) Prediction of abuse liability of drugs using IV self-administration by rats. Psychopharmacology 82:6-13.

Dal Bo G, St-Gelais F, Danik M, Williams S, Cotton M, Trudeau LE (2004) Dopamine neurons in culture express VGLUT2 explaining their capacity 
to release glutamate at synapses in addition to dopamine. J Neurochem 88:1398-1405.

Dal Bo G, Berube-Carriere N, Mendez JA, Leo D, Riad M, Descarries L, Levesque D, Trudeau LE (2008) Enhanced glutamatergic phenotype of mesencephalic dopamine neurons after neonatal 6-hydroxydopamine lesion. Neuroscience 156:59-70.

Di Chiara G, Imperato A (1988) Drugs abused by humans preferentially increase synaptic dopamine concentrations in the mesolimbic system of freely moving rats. Proc Natl Acad Sci U S A 85:5274-5278.

Dragunow M, Abraham W, Hughes P (1996) Activation of NMDA and muscarinic receptors induces nur-77 mRNA in hippocampal neurons. Brain Res Mol Brain Res 36:349-356.

Drevets WC, Gautier C, Price JC, Kupfer DJ, Kinahan PE, Grace AA, Price JL, Mathis CA (2001) Amphetamine-induced dopamine release in human ventral striatum correlates with euphoria. Biol Psychiatry 49:81-96.

Ekstrand MI, Terzioglu M, Galter D, Zhu S, Hofstetter C, Lindqvist E, Thams S, Bergstrand A, Hansson FS, Trifunovic A, Hoffer B, Cullheim S, Mohammed AH, Olson L, Larsson NG (2007) Progressive parkinsonism in mice with respiratory-chain-deficient dopamine neurons. Proc Natl Acad Sci U S A 104:1325-1330.

El-Ghundi M, O'Dowd BF, Erclik M, George SR (2003) Attenuation of sucrose reinforcement in dopamine D1 receptor deficient mice. Eur J Neurosci 17:851-862.

El Mestikawy S, Wallen-Mackenzie A, Fortin GM, Descarries L, Trudeau LE (2011) From glutamate co-release to vesicular synergy: vesicular glutamate transporters. Nat Rev Neurosci 12:204-216.

Everitt BJ, Robbins TW (2005) Neural systems of reinforcement for drug addiction: from actions to habits to compulsion. Nat Neurosci 8:1481-1489.

Franklin K, Paxinos G (2008) The mouse brain in stereotaxic coordinates, Ed 3. New York: Academic.

Gerhardt GA, Burmeister JJ (2000) Voltammetry in vivo for chemical analysis of the nervous system. In: Encyclopedia of analytical chemistry (Meyers RE, ed), pp 710-731. Hobroken, NJ: Wiley.

Gerhardt GA, Hoffman AF (2001) Effects of recording media composition on the responses of Nafion-coated carbon fiber microelectrodes measured using high-speed chronoamperometry. J Neurosci Methods 109:13-21.

Giros B, Jaber M, Jones SR, Wightman RM, Caron MG (1996) Hyperlocomotion and indifference to cocaine and amphetamine in mice lacking the dopamine transporter. Nature 379:606-612.

Gras C, Amilhon B, Lepicard EM, Poirel O, Vinatier J, Herbin M, Dumas S, Tzavara ET, Wade MR, Nomikos GG, Hanoun N, Saurini F, Kemel ML, Gasnier B, Giros B, El Mestikawy S (2008) The vesicular glutamate transporter VGLUT3 synergizes striatal acetylcholine tone. Nat Neurosci 11:292-300.

Hebert MA, Van Horne CG, Hoffer BJ, Gerhardt GA (1996) Functional effects of GDNF in normal rat striatum: presynaptic studies using in vivo electrochemistry and microdialysis. J Pharmacol Exp Ther 279: $1181-1190$.

Hnasko TS, Chuhma N, Zhang H, Goh GY, Sulzer D, Palmiter RD, Rayport S, Edwards RH (2010) Vesicular glutamate transport promotes dopamine storage and glutamate corelease in vivo. Neuron 65:643-656.

Hoffman AF, Lupica CR, Gerhardt GA (1998) Dopamine transporter activity in the substantia nigra and striatum assessed by high-speed chronoamperometric recordings in brain slices. J Pharmacol Exp Ther 287:487-496.

Hsiao S, Smith GP (1995) Raclopride reduces sucrose preference in rats. Pharmacol Biochem Behav 50:121-125.

Johnson PM, Kenny PJ (2010) Dopamine D2 receptors in addiction-like reward dysfunction and compulsive eating in obese rats. Nat Neurosci 13:635-641.

Kawano M, Kawasaki A, Sakata-Haga H, Fukui Y, Kawano H, Nogami H, Hisano S (2006) Particular subpopulations of midbrain and hypothalamic dopamine neurons express vesicular glutamate transporter 2 in the rat brain. J Comp Neurol 498:581-592.

Koob GF, Le Moal M (2001) Drug addiction, dysregulation of reward, and allostasis. Neuropsychopharmacology 24:97-129.

Luscher C, Malenka RC (2011) Drug-evoked synaptic plasticity in addiction: from molecular changes to circuit remodeling. Neuron 69:650-663.

Maggos CE, Tsukada H, Kakiuchi T, Nishiyama S, Myers JE, Kreuter J, Schlussman SD, Unterwald EM, Ho A, Kreek MJ (1998) Sustained withdrawal allows normalization of in vivo [11C]N-methylspiperone dopamine $\mathrm{D} 2$ receptor binding after chronic binge cocaine: a positron emission tomography study in rats. Neuropsychopharmacology 19: $146-153$.

Maheux J, Ethier I, Rouillard C, Levesque D (2005) Induction patterns of transcription factors of the nur family (nurr1, nur77, and nor-1) by typical and atypical antipsychotics in the mouse brain: implication for their mechanism of action. J Pharmacol Exp Ther 313:460-473.

Mendez JA, Bourque MJ, Dal Bo G, Bourdeau ML, Danik M, Williams S, Lacaille JC, Trudeau LE (2008) Developmental and target-dependent regulation of vesicular glutamate transporter expression by dopamine neurons. J Neurosci 28:6309-6318.

Moratalla R, Vickers EA, Robertson HA, Cochran BH, Graybiel AM (1993) Coordinate expression of $\mathrm{c}$-fos and jun $\mathrm{B}$ is induced in the rat striatum by cocaine. J Neurosci 13:423-433.

Moss J, Ungless MA, Bolam JP (2011) Dopaminergic axons in different divisions of the adult rat striatal complex do not express vesicular glutamate transporters. Eur J Neurosci 33:1205-1211.

Nestler EJ, Barrot M, Self DW (2001) DeltaFosB: a sustained molecular switch for addiction. Proc Natl Acad Sci U S A 98:11042-11046.

Olausson P, Jentsch JD, Tronson N, Neve RL, Nestler EJ, Taylor JR (2006) DeltaFosB in the nucleus accumbens regulates food-reinforced instrumental behavior and motivation. J Neurosci 26:9196-9204.

Peris J, Boyson SJ, Cass WA, Curella P, Dwoskin LP, Larson G, Lin LH, Yasuda RP, Zahniser NR (1990) Persistence of neurochemical changes in dopamine systems after repeated cocaine administration. J Pharmacol Exp Ther 253:38-44.

Porrino LJ, Lyons D, Smith HR, Daunais JB, Nader MA (2004) Cocaine self-administration produces a progressive involvement of limbic, association, and sensorimotor striatal domains. J Neurosci 24:3554-3562.

Pulipparacharuvil S, Renthal W, Hale CF, Taniguchi M, Xiao G, Kumar A, Russo SJ, Sikder D, Dewey CM, Davis MM, Greengard P, Nairn AC, Nestler EJ, Cowan CW (2008) Cocaine regulates MEF2 to control synaptic and behavioral plasticity. Neuron 59:621-633.

Rada P, Avena NM, Hoebel BG (2005) Daily bingeing on sugar repeatedly releases dopamine in the accumbens shell. Neuroscience 134:737-744.

Richardson NR, Roberts DC (1996) Progressive ratio schedules in drug selfadministration studies in rats: a method to evaluate reinforcing efficacy. J Neurosci Methods 66:1-11.

Sanchis-Segura C, Spanagel R (2006) Behavioural assessment of drug reinforcement and addictive features in rodents: an overview. Addict Biol 11:2-38.

Schuster CR, Thompson T (1969) Self administration of and behavioral dependence on drugs. Annu Rev Pharmacol 9:483-502.

Sclafani A (2006) Sucrose motivation in sweet "sensitive" (C57BL/6J) and "subsensitive" (129P3/J) mice measured by progressive ratio licking. Physiol Behav 87:734-744.

See RE, Elliott JC, Feltenstein MW (2007) The role of dorsal vs ventral striatal pathways in cocaine-seeking behavior after prolonged abstinence in rats. Psychopharmacology (Berl) 194:321-331.

Seeger TF, Gardner EL, Bridger WF (1981) Increase in mesolimbic electrical self-stimulation after chronic haloperidol: reversal by L-DOPA or lithium. Brain Res 215:404-409.

Shaham Y, Shalev U, Lu L, De Wit H, Stewart J (2003) The reinstatement model of drug relapse: history, methodology and major findings. Psychopharmacology (Berl) 168:3-20.

Small DM, Jones-Gotman M, Dagher A (2003) Feeding-induced dopamine release in dorsal striatum correlates with meal pleasantness ratings in healthy human volunteers. Neuroimage 19:1709-1715.

Stice E, Spoor S, Bohon C, Small DM (2008) Relation between obesity and blunted striatal response to food is moderated by TaqIA Al allele. Science 322:449-452.

Stuber GD, Hnasko TS, Britt JP, Edwards RH, Bonci A (2010) Dopaminergic terminals in the nucleus accumbens but not the dorsal striatum corelease glutamate. J Neurosci 30:8229-8233.

Tecuapetla F, Patel JC, Xenias H, English D, Tadros I, Shah F, Berlin J, Deisseroth K, Rice ME, Tepper JM, Koos T (2010) Glutamatergic signaling by mesolimbic dopamine neurons in the nucleus accumbens. J Neurosci 30:7105-7110.

Thomsen M, Caine SB (2006) Cocaine self-administration under fixed and progressive ratio schedules of reinforcement: comparison of C57BL/6J, 129X1/SvJ, and 129S6/SvEvTac inbred mice. Psychopharmacology (Berl) 184:145-154. 
Tremblay M, Rouillard C, Levesque D (1999) Dopamine D3 receptor antisense administration reduces basal c-fos and NGFI-B mRNA levels in the rat forebrain. Synapse 32:51-57.

Vanderschuren LJ, Di Ciano P, Everitt BJ (2005) Involvement of the dorsal striatum in cue-controlled cocaine seeking. J Neurosci 25:8665-8670.

Volkow ND, Wang GJ, Fowler JS, Logan J, Gatley SJ, Hitzemann R, Chen AD, Dewey SL, Pappas N (1997) Decreased striatal dopaminergic responsiveness in detoxified cocaine-dependent subjects. Nature 386:830-833.

Volkow ND, Fowler JS, Wang GJ, Baler R, Telang F (2008) Imaging dopamine's role in drug abuse and addiction. Neuropharmacology 56 [Suppl 1]:3-8.

Wallén-Mackenzie A, Gezelius H, Thoby-Brisson M, Nygard A, Enjin A, Fujiyama F, Fortin G, Kullander K (2006) Vesicular glutamate transporter 2 is required for central respiratory rhythm generation but not for locomotor central pattern generation. J Neurosci 26:12294-12307.

Wallén-Mackenzie A, Nordenankar K, Fejgin K, Lagerstrom MC, Emilsson L, Fredriksson R, Wass C, Andersson D, Egecioglu E, Andersson M, Strandberg J, Lindhe O, Schioth HB, Chergui K, Hanse E, Langstrom B,
Fredriksson A, Svensson L, Roman E, Kullander K (2009) Restricted cortical and amygdaloid removal of vesicular glutamate transporter 2 in preadolescent mice impacts dopaminergic activity and neuronal circuitry of higher brain function. J Neurosci 29:2238-2251.

Wang GJ, Volkow ND, Logan J, Pappas NR, Wong CT, Zhu W, Netusil N, Fowler JS (2001) Brain dopamine and obesity. Lancet 357:354-357.

Welter M, Vallone D, Samad TA, Meziane H, Usiello A, Borrelli E (2007) Absence of dopamine D2 receptors unmasks an inhibitory control over the brain circuitries activated by cocaine. Proc Natl Acad Sci U S A 104:6840-6845.

Wolf ME (2010) The Bermuda Triangle of cocaine-induced neuroadaptations. Trends Neurosci 33:391-398.

Xu M, Hu XT, Cooper DC, Moratalla R, Graybiel AM, White FJ, Tonegawa S (1994) Elimination of cocaine-induced hyperactivity and dopaminemediated neurophysiological effects in dopamine D1 receptor mutant mice. Cell 79:945-955.

Yamaguchi T, Wang HL, Li X, Ng TH, Morales M (2011) Mesocorticolimbic glutamatergic pathway. J Neurosci 31:8476-8490. 